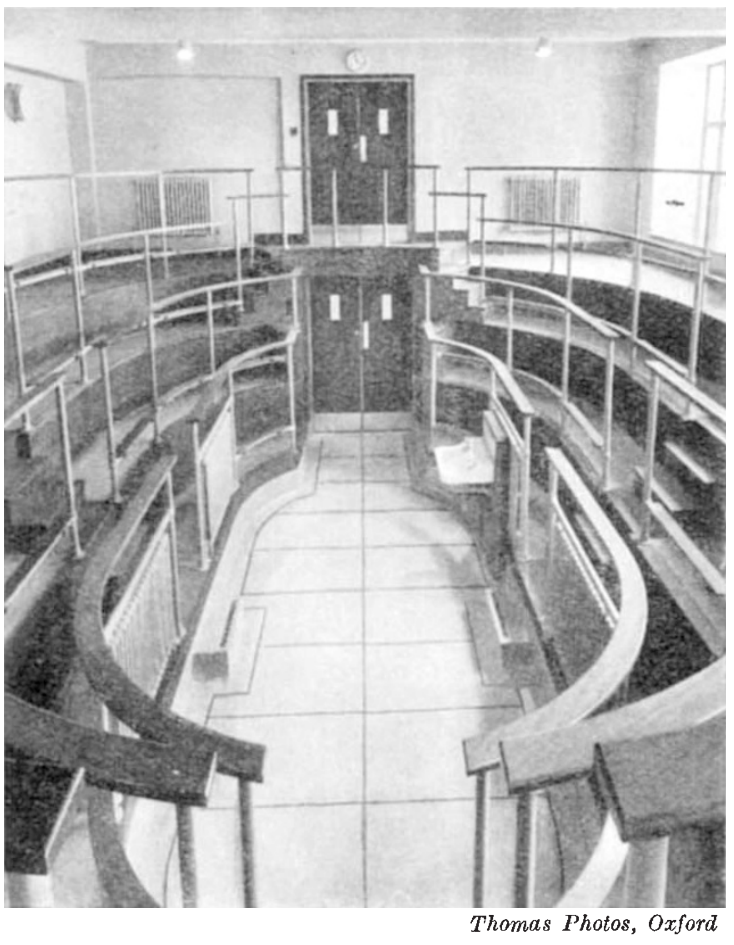

Fig. 2. Demonstration theatre

the photographic studio. Research accommodation on this floor comprises three suites of small interconnected rooms adapted to the needs of microscopical work.

The third floor opens out on to a large area of the whole length of the second-floor roof, which can be used for experimental work on muscular exercise, the subjects' courses being timed from the bay windows of a special observation room. On this floor are the operating theatre and X-ray room; an observation room for the psychological testing of small and large primates; and a spacious and well-ventilated animal house, which includes a sound-proofed dog-kennel room.

The Laboratory has been designed with the view of maximum adaptability of purpose. Rooms filled with extensive and permanent bench installations are few, and most of the classrooms and research rooms could be differently divided and furnished from time to time, as changing interests and emphasis may require.

Enough has probably been said to show that Oxford's problem of inadequate bench space for physiology has been solved. Elementary instruction will now be possible without strain ; and a start can be made with the re-expansion of the content of the courses in advanced physiology. The extent and direction of this expansion must, of course, depend on the interests of the research workers who form the teaching staff. Its pace will depend on the rate at which financial stringency will allow reinforcement of their numbers to a level which will restore the student-teacher ratios of the senior classes of former days. For there is to be no weakening of the traditional policy which strives to place before the large majority of Oxford medical students educational opportunities which are elsewhere restricted to men and women proposing to specialize in biological research.

\section{NINTH INTERNATIONAL CONGRESS OF GENETICS}

$\mathrm{T}$

HE post-war trend in international scientific meetings has been towards small symposia and conferences, and, as a consequence, there are now considerable opportunities for contact between those working within each of a number of limited fields. The main function of international congresses has become the complementary one of discussion between workers in different branches of broader fields. On this standard, the Ninth International Congress of Genetics, held this year in Bellagio during August 24-31, has been more successful than the two preceding ones (Edinburgh, 1939; Stockholm, 1948), and the organizing committee deserves the gratitude of all the members who participated.

The reasons for this success are essentially twofold. First, the number of participants-more than eight hundred-though somewhat larger than at the Eighth Congress, was still small enough for everyone to meet everyone else. With numbers exceeding, say, one thousand, personal contacts outside the sessions can only be selective and require deliberate planning. Second, the Congress was centred not on a town but on a small and quiet holiday resort. In Bellagio, members of the Congress were accommodated in hotels along a short stretch of the shore, and most of the cafés were in the same stretch : thus meeting, or looking for, any member outside session time was only a matter of walking a few yards. Unfortunately, Bellagio could not accommodate all the members: part were accommodated ten minutes away by boat across the lake, and the two groups became effectively separated in the evening.

The plenary sessions of the Congress were held in the dining-hall of a big hotel, with unsatisfactory acoustics and ventilation, and the sectional sessions were held in the classrooms of a local school, some of insufficient capacity. These shortcomings were the price to be paid for by choosing a locality without the facilities of a university, but it was well worth paying in view of the other advantages. There are two lessons which this Congress has brought home. One is that the main purpose of a congress can be achieved only if the numbers are kept well below the thousand mark. The other is that a small centre is preferable to a large town; if it could also have lecture-room facilities of university standard, then so much the better.

The work of the Congress was arranged in a novel way. The afternoons were reserved exclusively for plenary sessions, each with three or four invited papers-twenty-seven in all. During the mornings there were eight special sessions simultaneously for papers of fifteen minutes length (about three hundred in all). These special sessions were interspersed with invited lectures (fourteen in number), not overlapping with one another.

It would be impossible to give here more than an idea of trends in genetics, as detectable at the Congress.

The study of the part the genes play in the function of the cell, and secondarily in the organism, has become one of the central fields in genetics. This trend can be detected quite clearly even in indirect approaches : for example, researches on the arrangement of the genes along the chromosomes, on the induction of specific mutations, on the process of mutation itself, and even on quantitative inheritance, 
are all strongly biased towards this functional aspect. The opening address of the president, Prof. Richard Goldschmidt, on what he called the dynamic versus the static approach in genetics, put into a nutshell what became increasingly clear as the work of the Congress proceeded.

Another impression from the papers presented at the Congress is that the microscopic study of the chromosomes has reached an impasse, except as a branch of comparative morphology : it is waiting for substantially new techniques and substantially new ideas. As for the former, there was one demonstration on electron microscopy of chromosomes in meiosis which was of enough interest to suggest that this might be one of the new techniques.

The genus Drosophila has now come back into its own for a new purpose: the study of natural populations. Under the stimulus of genetic investigation so much work has been done on the systematics, the ecology, the comparative anatomy (including comparative karyology) of the innumerable species of Drosophila that this genus is now the ideal tool in this field.

The numerous papers presented showed that the interest in quantitative inheritance has expanded enormously since the last Congress. If its exponents can keep the distinction between statistical tools and biological ends clear, this is obviously a field of great future importance.

As to human genetics, there is a growing interest both in the study of inheritance of particular conditions and of the comparative genetics of populations. Indeed, man talies now a rank not far from that of Drosophila and of micro-organisms as a subject for genetic research.

The Congress will certainly give fruits both in the direction of personal friendship, renewed or promoted de novo, and of new ideas arising from cross-fertilization.

G. Pontecorvo

\section{INDUSTRIAL RESEARCH DIRECTORS}

T THE report of the third Conference of Industrial Research Directors and Research Managers, organized by the Industrial Research Committee of the Federation of British Industries, which was held at Ashorne Hill during April 17-19, 1953, has now been published*. The main subject of the conference was the commercial utilization of research results, and the report thus deals with an aspect of productivity with which the Advisory Council on Scientific Policy and the Department of Scientific and Industrial Research are increasingly concerned. Dealing with the problem from the point of view of company management, Lord Baillieu, who outlined policy and practice in the Dunlop Rubber Co., urged that it is essential to operate within our resources of finance, man-power and equipment. Research programmes should be conceived and keenly reviewed in terms of the conditions which a new idea or discovery must meet to achieve success; but we should not lose sight of the wider horizons and fundamental researches which have challenged the ingenuity and courage of men, and to which the British genius has responded so outstandingly. From the production

* Federation of British Industries. Report of the Third Conference of Industrial Directors and Managers, Ashorne Hill, 1953. Pp. vi+ point of view, Mr. G. S. Samways thought that in the metal container industry science has opened the way to revolutionary rather than evolutionary changes; research presents a problem not in finding ideas or in the method of implementation, but in finding the right type of young men and the large capital investment required. From the research point of view, Dr. N. P. Inglis urged the importance of a full and harmonious relationship between research and production departments. Elimination of problems of understanding, communications, joint consultation, etc., is largely a matter of personnel, and particularly of securing the right personnel and moving them about in the right way in their early years. Mr. E. R. Davies, describing the relations between research work and production in Kodak, Ltd., emphasized the way in which collaboration between plant and research workers is fostered by frequent informal as well as formal contacts, though the manufacturing departments are not paralleled entirely by laboratory groups in the research department; the four main types of manufacturing activity have been kept successfully in touch with development work and research groups through a system of four senior co-ordinators. Mr. J. B. Mitford stated that in Fibreglass, Ltd., the production department looks to the research department for new manufacturing methods, or revolutionary improvements in existing methods, for the rapid tracing and elimination of eauses of trouble in regular manufacture, and for the provision of a testing and advisory service on raw materials and finished products. Frequently, he admitted, the production side is at fault in failing to give the whole of the facts, and he stressed the necessity of research and development men establishing a high reputation with the junior management and production people at the foremen-level.

The papers on utilization of research results as a sales problem, whether from the sales or the research point of view, and the subsequent discussion indicated that it is not quite so easy to establish a satisfactory relation between research and sales departments as between research and production departments. The essential point seems to be to maintain a proper balance and relation in the traffic of ideas between the two departments, and it is desirable that the practical experience of the sales side should receive full consideration in any dis. cussions on the shaping of research and the evaluation of research progress. There is a place for creativeminded scientists with commercial instincts in the sales organization, in order to digest the import of sales intelligence and translate it into research ideas; but Dr. H. E. Merritt pointed out that it is also essential that the product situation should be reviewed, past performance appraised and probable future trends analysed at a high level in management. Much discussion centred on the training of salesmen, though the need for technical training was also fully recognized.

The fourth session was concerned with creating the right atmosphere. This, Mr. H. C. H. Graves urged, is partly a matter of human relations, and he thought there is room for some research into administrative methods, etc., of improving co-operation. If the importance, integrity and dignity of the individual are recognized, group attitudes would adjust themselves satisfactorily: the important thing is to encourage the right overall attitude to the economic objectives of the firm and industry, and appreciation 